\title{
GAMBARAN KEJADIAN ASFIKSIA DENGAN LILITAN TALI PUSAT PADA BAYI BARU LAHIR DI UPTD PUSKESMAS LAMURUKUNG TAHUN 2017
}

\author{
Mustar \\ AKBID Bina Sehat Nusantara Bone \\ Alamat korespondensi : (mustarbabullah@yahoo.com/082188442002)
}

\begin{abstract}
ABSTRAK
Lilitan tali pusat dapat menyebabkan asfiksia dimana asfiksia pada Bayi Baru lahir merupakan masalah yang penting karena dapat meningkatkan morbiditas dan mortalitas pada bayi baru lahir. Lilitan tali pusat ini sendiri dapat mengakibatkan suatu kejadian fatal yaitu kematian bayi, karena puntiran tali pusat yang berulang-ulang ke satu arah tersebut mengakibatkan atus darah dari ibu ke janin tersumbat total. Tujuan : Untuk mengetahui Gambaran Kejadian Asfiksia dengan Lilitan Tali Pusat Pada Bayi Baru Lahir. Metode : Penelitian ini dilakukan secara deskriptif dengan menggunakan data sekunder UPTD Puskesmas Lamurukung. Hasil : Berdasarkan hasil penelitian yang telah dilakukan di UPTD Puskesmas Lamurukung dengan data sekunder pada tahun 2017 mengenai gambaran kejadian asfiksia dengan lilitan tali pusat di UPTD Puskesmas Lamurukung dengan variabel umur ibu, paritas dan umur kehamilan dapat disimpulkan bahwa dari 26 bayi yang mengalami asfiksia terdapat 12 bayi asfiksia karena lilitan tali pusat. Karakteristik responden kejadian asfiksia dengan lilitan tali pusat paling banyak pada kelompok umur dibawah 20 tahun yaitu sebesar $41,7 \%$ dan umur $20-35$ tahun sebesar $41,7 \%$, variabel paritas terbanyak pada persalinan primipara yaitu sebesar $50 \%$ dan variabel umur kehamilan terbesar yaitu bayi prematur sebesar $66,7 \%$. Kesimpulan : Dari 26 bayi yang mengalami asfiksia 12 bayi $(46,2 \%)$ disebabkan oleh lilitan tali pusat.
\end{abstract}

Kata Kunci : Asfiksia, lilitan tali pusat, umur ibu, paritas, kehamilan

\section{PENDAHULUAN}

Lilitan tali pusat dapat menyebabkan asfiksia dimana asfiksia pada Bayi Baru lahir merupakan masalah yang penting karena dapat meningkatkan morbiditas dan mortalitas pada bayi baru lahir. Adanya lilitan tali pusat di leher dalam kehamilan menurutnya, pada umumnya tidak menimbulkan masalah. Namun dalam proses persalinan dimana mulai timbul kontraksi rahim dan kepala janin mulai turun dan memasuki rongga panggul, maka lilitan tali pusat menjadi semakin erat dan menyebabkan penekanan atau kompresi pada pembuluh-pembuluh darah tali pusat. Akibatnya, suplai darah yang mengandung oksigen dan zat makanan ke janin akan berkurang, yang mengakibatkan janin menjadi sesak atau hipoksia. Lilitan tali pusat ini sendiri dapat mengakibatkan suatu kejadian fatal yaitu kematian bayi. Karena puntiran tali pusat yang berulang-ulang ke satu arah tersebut mengakibatkan atus darah dari ibu ke janin tersumbat total. Lilitan tali pusat pada bayi yang terlalu erat sampai dua atau tiga kali bisa menyebabkan kompresi tali pusat sehingga janin mengalami kekurangan oksigen. Selain itu angka kematian dikarenakan asfiksia juga masih tinggi dan masih merupakan wewenang bidan dalam memberikan manajemen asuhan kebidanan.
Angka Kematian Bayi (AKB) merupakan salah satu indikator untuk mengetahui derajat kesehatan di suatu negara seluruh dunia. AKB di Indonesia masih sangat tinggi, menurut hasil Survei Demografi Kesehatan Indonesia (SDKI) tahun 2016 bahwa AKB di Indonesia pada tahun 2015 mencapai 31/1000 KH (kelahiran hidup). Apabila dibandingkan dengan target dalam Millenium Development Goals (MDGs) ke-4 tahun 2015 yaitu 17/1000 $\mathrm{KH}$, ternyata $\mathrm{AKB}$ di Indonesia masih sangat tinggi.

Berdasarkan data dari Profil Dinas Kesehatan Provinsi Sulawesi Selatan tahun 2017 di Sulawesi Selatan tahun 2016 angka kematian neonatal sebesar 838 kasus sedangkan angka kematian neonatal sebesar 5.64 per 1.000 kelahiran hidup.

Menurut data dari dinas kesehatan Kab. Bone menyatakan angka kematian neonatal tahun 2016 sebanyak 83 bayi dan tahun 2017 61 bayi, sedangkan yang mengalami asfiksia tahun 2016 sebanyak 102 bayi dan mengalami peningkatan di tahun 2017 yaitu sebanyak 131 bayi. (Dinkes Kab. Bone, 2017)

Dari hasil studi yang dilakukan oleh Elisa Damayanti yang berjudul faktor-faktor yang mempengaruhi kejadian asfiksia neonatorum di RS PKU Muhammadiyah Yogyakarta tahun 2008 menyatakan bahwa 
lilitan tali pusat menjadi salah satu penyebab terjadinya asfiksia dengan $\mathrm{OR}>1$ yaitu 1,74.

Kemudian hasil data yang diperoleh dari hasil pencatatan dan pelaporan di UPTD PKM Lamurukung pada tahun 2017 jumlah kelahiran yaitu 203 kelahiran, dari jumlah tersebut terdapat 26 bayi baru lahir yang mengalami asfiksia, kemudian bayi yang hidup 23 bayi dan tiga bayi yang meninggal, bayi yang mengalami asfiksia karena lilitan tali pusat yaitu sebanyak 12 bayi, kemudian bayi yang mengalami asfiksia karena prematur yaitu sebanyak 8 bayi, karena partus lama sebanyak 5 bayi dan karena letak sungsang sebanyak 1 bayi. (UPTD PKM Lamurukung, 2018)

Berdasarkan data diatas tidak sedikit bayi yang lahir di UPTD Puskesmas Lamurukung mengalami kasus asfiksia karena lilitan tali pusat. Namun hal ini, belum ada yang berusaha melakukan penelitian untuk menelusuri penyebab kejadian tersebut. Oleh karena itu, sebagai calon tenaga kesehatan dengan melihat kejadian tersebut saya sangat tertarik untuk melakukan mengenai "Gambaran Kejadian Asfiksia Dengan Lilitan Tali Pusat Pada Bayi Baru Lahir di UPTD Puskesmas Lamurukung Tahun 2017 ". Agar bisa menjadi landasan untuk peneliti lain dalam melakukan penelitian selanjutnya.

\section{BAHAN DAN METODE}

Lokasi, populasi, sampel

Lokasi penelitian ini di UPTD Puskesmas Lamurukung. Populasi dalam penelitian ini adalah seluruh bayi baru lahir yang lahir dengan asfiksia Tahun 2017 yaitu 26 bayi. Sampel penelitian ini adalah seluruh bayi baru lahir yang lahir dengan asfiksia karena lilitan tali pusat yaitu 12 bayi di Tahun 2017.

1. Kriteria Inklusi :

Data Bayi baru lahir dengan Asfiksia akibat lilitan tali pusat tahun 2017

2. Kriteria Ekslusi

Data Bayi Asfiksia bukan Karena Lilitan tali pusat.

\section{Pengumpulan Data}

1. Data sekunder adalah data yang diperoleh dalam bentuk jadi dan telah diolah oleh pihak lain yang biasanya dalam bentuk publikasi.

2. Data primer adalah data yang dikumpulkan dan diolah sendiri oleh suatu organisasi atau perorangan langsung dari objeknya (Saryono 2014).
Pengolahan Data

1. Editing

Editing adalah tahapan kegiatan memeriksa validitas data yang masuk seperti memeriksa kelengkapan pengisian kuesioner, kejelasan jawaban, relevansi jawaban dan keseragaman suatu pengukuran.

2. Coding

Coding adalah tahapan kegiatan mengklasifikasi data dan jawaban menurut kategori masing-masing sehingga memudahkan dalam pengelompokan data.

3. Processing

Processing adalah tahapan kegiatan memproses data agar dapat dianalisis. Pemrosesan data dilakukan dengan cara memasukkan data hasil pengisian kuesioner ke dalam master tabel.

4. Cleaning

Cleaning yaitu tahapan kegiatan pengecekan kembali data yang sudah di masukkandan melakukan koreksi bila terdapat kesalahan. (Lapau, 2013).

\section{Analisis Data}

Analisis Univariat

Pada hasil pengolahan data dilakukan analisa secara univariat, yaitu untuk mengetahui distribusi frekuensi dari masing-masing variabel yang diteliti.

\section{HASIL PENELITIAN}

Tabel 1. Gambaran kejadian asfiksia karena lilitan tali pusat tahun $2017(\mathrm{n}=26)$

\begin{tabular}{|c|c|c|}
\hline \multirow{2}{*}{ Bayi Asfiksia karena } & \multicolumn{2}{|c|}{2017} \\
\cline { 2 - 3 } & $\mathrm{n}$ & $\%$ \\
\hline Lilitan tali pusat & 12 & 46,2 \\
\hline Sebab lain & 14 & 53,8 \\
\hline Jumlah & 26 & 100 \\
\hline
\end{tabular}

Dari hasil penelitian yang didapatkan di UPTD puskesmas Lamurukung tahun 2017 sebanyak 12 (46,2 \%) bayi Asfiksia karena lilitan tali pusat dari 26 bayi baru lahir dan 14 (53,8\%) bayi asfiksia dengan diagnosis yang bervariasi.

Tabel 2 gambaran kejadian asfiksia karena lilitan tali pusat dilihat dari umur ibu tahun.

\begin{tabular}{|c|c|c|}
\hline \multirow{2}{*}{ Umur ibu } & \multicolumn{2}{|c|}{2017} \\
\cline { 2 - 3 } & $\mathrm{n}$ & $\%$ \\
\hline$<20$ tahun & 5 & 41,7 \\
\hline 20 -35 tahun & 5 & 41,7 \\
\hline$>35$ tahun & 2 & 16,6 \\
\hline Jumlah & 12 & 100 \\
\hline
\end{tabular}

Dari hasil penelitian yang didapakan di UPTD Puskesmas Lamurukung tahun 
2017 bayi yang lahir asfiksia karena lilitan tali pusat dilihat dari aspek umur ibu yaitu ada sebanyak $5 \quad(41,7 \%) \quad$ ibu yang melahirkan di bawah umur 20 tahun, 5 $(41,7 \%)$ ibu yang melahirkan umur 20-35 tahun dan $2(16,6 \%)$ ibu yang melahirkan umur di atas 35 tahun.

Tabel 3 gambaran kejadian asfiksia karena lilitan tali pusat dilihat aspek paritas tahun $2017(n=12)$

\begin{tabular}{|c|c|c|}
\hline \multirow{2}{*}{ Paritas } & \multicolumn{2}{|c|}{2017} \\
\cline { 2 - 3 } & $\mathrm{n}$ & $\%$ \\
\hline Primipara & 6 & 50 \\
\hline Multipara & 4 & 33,3 \\
\hline Grandemultipara & 2 & 16,7 \\
\hline Jumlah & 12 & 100 \\
\hline
\end{tabular}

Dari hasil penelitian yang didapakan di UPTD Puskesmas Lamurukung tahun 2017 bayi yang lahir asfiksia karena lilitan tali pusat dilihat dari aspek paritas menunjukkan sebagian besar dialami primipara sebanyak $6 \quad(50 \%)$ ibu, sedangkan multipara sebanyak $4(33,3 \%)$ ibu dan grandemultipara sebanyak $2(16,6$ \%) ibu.

Tabel 4 gambaran kejadian asfiksia karena lilitan tali pusat dilihat dari umur kehamilan tahun $2017(\mathrm{n}=12)$

\begin{tabular}{|c|c|c|}
\hline \multirow{2}{*}{ Paritas } & \multicolumn{2}{|c|}{2017} \\
\cline { 2 - 3 } & $\mathrm{n}$ & $\%$ \\
\hline Prematur & 8 & 66,7 \\
\hline Matur & 4 & 33,3 \\
\hline Postmatur & 0 & 0 \\
\hline Jumlah & 12 & 100 \\
\hline
\end{tabular}

Dari hasil penelitian yang didapakan di UPTD Puskesmas Lamurukung tahun 2017 bayi yang lahir asfiksia karena lilitan tali pusat dilihat dari aspek umur kehamilan menunjukkan sebagian besar dialami ibu dengan kehamilan berusia prematur yaitu sebanyak $8 \quad(66,7 \%)$ ibu sedangkan kehamilan cukup bulan atau matur sebanyak $4(33,3 \%)$ ibu.

\section{PEMBAHASAN}

Dari 26 responden yang diteliti, kejadian asfiksia terbanyak yaitu karena penyebab lain sebanyak 14 bayi $(53,8 \%)$ dibandingkan dengan asfiksia karena lilitan tali pusat sebanyak 12 bayi (46,2\%). Lilitan tali pusat adalah tali pusat yang dapat membentuk lilitan sekitar badan ,bahu, tungkai atas/ bawah dan leher pada bayi. Keadaan ini dijumpai pada ait ketuban yang berlebihan, tali pusat yang panjang, dan bayinya yang kecil.
Lilitan tali pusat bisa terjadi dimana saja dari tubuh janin. Tetapi yang sering terjadi adalah bagian leher (nuchal cord). Hal ini dapat menyebabkan suplai oksigen ke janin berkurang sehingga dapat terjadi asfiksia. Kompresi umbilikus akan mengakibatkan terganggunya aliran darah dalam pembuluh darah umbilikus dan menghambat pertukaran gas antara ibu \& janin (Prawirohardjo, 2005).

1. Kejadian asfiksia karena lilitan tali pusat berdasarkan variabel umur ibu

Berdasarkan penelitian di atas kejadian asfiksia karena lilitan tali pusat berdasarkan umur ibu, terjadi paling banyak pada umur di bawah 20 tahun dan umur 20 sampai 35 tahun yaitu masingmasing sebanyak 5 responden $(41,7 \%)$ sedangkan untuk umur diatas 35 tahun sebanyak 2 responden (16,6\%). Data tersebut dapat disimpulkan bahwa gambaran umur ibu memberikan pengaruh terhadap kejadian asfiksia karena lilitan tali pusat.

Adapun klasifikasi usia ibu melahirkan menurut Coirul (2011) yaitu usia reproduktif (20 tahun -35 tahun). Usia tersebut cukup aman untuk melahirkan. Di usia inilah calon bayi terbilang dalam masa aman dalam proses pembentukannya. Usia resiko tinggi ( $<20$ tahun dan $>35$ tahun), pada usia $<20$ tahun beresiko karena ibu belum siap secara medis (organ reproduksi) maupun secara mental.

Menurut Teori dari segi kesehatan ibu yang berumur $<20$ Tahun rahim dan panggul belum berkembang dengan baik, begitu sebaliknya yang berumur $>35$ Tahun kesehatan dan keadaan rahim tidak sebaik seperti saat ibu berusia 20-35 tahun. Umur Ibu $<20$ Tahun dan $>35$ Tahun merupakan umur yang tidak reproduktif atau umur tersebut termasuk dalam resiko tinggi kehamilan.

Pada primigravidausia yang kurang dari 20 tahun memiliki resiko mengalami komplikasi persalinan dan komplikasi perinatal yang lebih tinggi yaitu peningkatan kejadian BBLR, asfiksia, persalinan preterm, lahir mati, persalinan pervaginam dengan bantuan instrument (Widiprianita, 2010 dalam Wulandari Priharyanti, 2015. Faktor -faktor yang berhubungan dengan kejadian asfiksia neonatorum di ruang melati RSUD Dr. $\mathrm{H}$. Soewondo Kendal).

Umur ibu adalah salah satu faktor yang berhubungan dengan kejadian asfiksia neonatorum yang erat kaitannya dengan kejadian lilitan tali pusat. Hal ini sejalan dengan penelitian yang dilakukan 
oleh Katriningsih (2009), bahwa umur ibu mempengaruhi terjadinya asfiksia neonatorum. Demikian juga dengan penelitian yang dilakukan oleh Novisye Katiandagho (2015) bahwa umur ibu mempengaruhi terjadinya lilitan tali pusat yang dapat menyebabkan asfiksia sedang pada bayi baru lahir. Hasil yang berbeda dikemukanan oleh hasil penelitian yang dilakukan Seri (2017) bahwa umur ibu tidak berpengaruh terhadap kejadian asfiksia karena lilitan tali pusat, hal ini dikarenakan faktor ibu bukan merupakan penyebab langsung terjadinya asfiksia.

2. Kejadian asfiksia karena lilitan tali pusat berdasarkan variabel paritas

Berdasarkan penelitian di atas kejadian asfiksia karena lilitan tali pusat berdasarkan paritas, kejadian asfiksia karena lilitan tali pusat terbanyak pada kelompok primipara yaitu sebanyak 6 responden $(50 \%)$ kemudian multipara sebanyak 4 responden (33,3\%), sedangkan untuk kelompok grandemultipara sebanyak 2 responden $(16,7 \%)$. Data tersebut dapat disimpulkan gambaran paritas memberikan pengaruh terhadap kejadian asfiksia neonatorum dengan lilitan tali pusat.

Hasil penelitian ini sesuai dengan penelitian sebelumnya yang dilakukan oleh Junita (2014) dan Novisye (2015) bahwa terdapat hubungan antara paritas dengan kejadian asfiksia karena lilitan tali pusat. Hasil yang berbeda dikemukakan oleh hasil penelitian yang dilakukan Gilang et al (2015) yang menyatakan bahwa jumlah paritas tidak berhubungan dengan kejadian asfiksia neonatorum dan lilitan tali pusat.

Paritas adalah jumlah bayi yang dilahirkan ibu hamil, paritas yang aman sampai dengan tiga kelahiran. Jumlah anak lebih dari tiga dapat meningkatkan resiko komplikasi persalinan (Purwanto, A, 2005 dalam Wulandari Priharyanti, 2015. Faktorfaktor yang berhubungan dengan kejadian asfiksia neonatorum di ruang melati RSUD Dr. H. Soewondo Kendal) .

Paritas yang rendah (paritas satu) menunjukkan ketidaksiapan ibu dalam menangani komplikasi yang terjadi dalam kehamilan, persalinan dan nifas. Paritas I beresiko karena ibu belum siap secara medis dan mental. Paritas yang tinggi memungkinkan teradinya penyulit kehamilan dan persalinan yang dapat menyebabkan terganggunya transport oksigen dari ibu ke janin yang akan menyebabkan asfiksia yang dapat dinilai dari APGAR score menit pertama setelah lahir (Manuaba, 2010).

3. Kejadian asfiksia karena lilitan tali pusat berdasarkan variabel umur kehamilan

Berdasarkan penelitian di atas kejadian asfiksia dengan lilitan tali pusat berdasarkan umur kehamilan terbanyak pada kehamilan prematur sebanyak 8 responden $(66,7 \%)$ dan ,matur sebanyak 4 responden $(33,3 \%)$. Dari data tersebut dapat diasumsikan bahwa gambaran variabel umur kehamilan memberikan pengaruh terhadap kejadian asfiksia dengan lilitan tali pusat.

Pada usia kehamilan sebelum 8 bulan (prematur) umumnya kepala janin belum memasuki bagian atas panggul. Pada saat itu ukuran bayi relative kecil dan jumlah air ketuban berlebihan, kemungkinan bayi terlilit talipusat (Gilang, 2010.

\section{KESIMPULAN}

1. Kejadian asfiksia dengan lilitan tali pusat berdasarkan umur ibu, terjadi paling banyak pada umur di bawah 20 tahun dan umur antara 20 sampai 35 tahun yaitu masing-masing sebanyak 5 responden $(41,7 \%)$.

2. Kejadian asfiksia dengan lilitan tali pusat berdasarkan paritas, kejadian asfiksia karena lilitan tali pusat terbanyak pada kelompok primipara yaitu sebanyak 6 responden $(50 \%)$

3. Kejadian asfiksia dengan lilitan tali pusat berdasarkan umur kehamilan terbanyak pada kehamilan prematur sebanyak 8 responden $(66,7 \%)$.

\section{SARAN}

1. Bagi tempat penelitian

Diharapkan penelitian ini dapat berguna sebagai masukan bagi puskesmas dalam penanganan bagi bayi dengan lilitan tali pusat dan meningkatkan pelayanan ibu hamil khususnya tentang larangan melakukan tindakan pengurutan perut.

2. Bagi institusi.

Diharapkan penelitian ini dapat digunakan sebagai bahan acuan pembelajaran sebagai bentuk nyata mengenai keadaan lahan praktek.

3. Bagi masyarakat

Diharapkan penelitian ini dapat menjadi bahan membelajaran dan perbandingan bagi masyarakat bahwa betapa pentingnya melakukan pemeriksaan kehamilan secara teratur sehingga dapat mengurangi resikoresiko yang dapat membahayakan ibu dan janin. 


\section{DAFTAR PUSTAKA}

Baety, A. N. 2011. Biologi reproduksi kehamilan dan persalinan. Edisi I. Yogyakarta: Graha ilmu

Fraser M. D. Mayles. 2009. Buku ajar bidan. Jakarta: EGC

Manuaba, 2010. IImu kebidanan penyakit kandungan dan keluarga berencana. Jakarta: EGC

Prawirohardjo Sarwono, 2005. Ilmu kebidanan. Jakarta: YBP-SP

Rohani, dkk, 2011. Asuhan pada masa persalinan. Jakarta: Salemba Medika

Rukiyah Ai Yeyeh dan Yulianti Lia, 2010. Asuhan neonatus. Jakarta: Trans Info Media

Sari, Wening, 2013. Panduan lengkap kesehatan wanita. Jakarta: Penebar Swadaya Grup 